ECCOMAS

Proceedia
COMPDYN 2021

$8^{\text {th }}$ ECCOMAS Thematic Conference on Computational Methods in Structural Dynamics and Earthquake Engineering

M. Papadrakakis, M. Fragiadakis (eds.) Streamed from Athens, Greece, 28 - 30 June 2021

\title{
COMPARISON BETWEEN DYNAMIC NONLINEAR ANALYSIS WITH ASCE 7-10 AND ASCE 7-16 IN CONCRETE FRAMES WITH VISCOUS DAMPERS INCORPORATED
}

\author{
Juan S. Cundumi García ${ }^{1}$, and Orlando Cundumi Sánchez ${ }^{2}$ \\ ${ }^{1}$ Pontificia Universidad Javeriana, Cali, Colombia \\ Calle18\#118-250 Avenida Cañasgordas, Cali-Colombia \\ e-mail: cundumi0612@javerianacali.edu.co \\ e-mail: sebastian_cundumi_ing@hotmail.com \\ ${ }^{2}$ Pontificia Universidad Javeriana, Cali, Colombia \\ Calle18\#118-250 Avenida Cañasgordas, Cali-Colombia \\ e-mail: Orlando.cundumi@javerianacali.edu.co
}

\begin{abstract}
During the last few years, different methodologies have been developed for the analysis of the structural seismic response, such as the performance-based design, the systems of energy dissipation, seismic isolation. Based on these efforts, a number of devices, known collectively as protection systems have emerged. They are divided into three types of systems: passive, active, and semi-active. Passive systems dissipate energy through friction, viscous fluid dampers, and inelastic behavior of the material, among others. On the other hand, active control systems can be implemented by applying time varying forces to counteract those imposed by the excitation. which can be active, passive, semi-active, active, etc.

This paper presents the response of the structure when it enters the nonlinear range and is being controlled by the Viscous Damper. To obtain the nonlinear response of the structure system through numerical simulation are used the Methodologies of ASCE 7-10 and ASCE 716. To examine the behavior of the structures and the application of each methodology, simulations using concrete frames of 5, 7 and 11-story buildings were performed. The models were subjected to the horizontal components of different earthquakes, for the ASCE 7-10 were used three earthquakes, for the ASCE 7-16 were used seven earthquakes. These seismic records are subjected to a matching process to obtain records that match the corresponding building code design spectrum for a high seismic risk zone. The history displacement and acceleration results were compared with those obtained with the uncontrolled structure with nonlinear behavior.
\end{abstract}

Keywords: Energy Dissipation System, Dynamic Nonlinear Analysis, Spectral Matching, 


\section{INTRODUCTION}

During the last three decades, a number of modern mechanical devices have been proposed to reduce the structural response of buildings to environmental loads. These devices, which are known collectively as protective devices, include viscoelastic dampers, viscous fluid dampers, frictional dampers, tuned-mass dampers, and base isolation systems. The devices themselves and their design methodology are referred to as passive control systems [1]. On the other hand, the highest level of sophistication in seismic protection is provided by the active control systems [2]. There is an intermediate alternative between passive and fully active control systems: they are referred to as "semi-active systems" $[3,4,5,11,12]$, The passive systems dissipate the seismic energy through friction in special devices, the inelastic behavior of sacrificial elements, etc. The passive systems have the important advantage that they do not require external energy for their operation.

On the other hand, research on fragility curves in structures with control system incorporated have been developed Taylor and Dike [13], Cundumi and Laboy [6], and among others.

This can be achieved by incorporating control systems to reduce displacements, acceleration and forces among seismic events. Incorporating control systems as an alternative for the design of new structures and the rehabilitation of existing structures is becoming more popular among building codes. Some examples of this Code include the Colombian Code NSR-10 [16], ASCE 7-10 and ASCE 7-16 (American Society of Civil Engineers) [17, 18], the Eurocode [30], and the Chilean Standard NCh [27].

This paper only presents the result abstained for two frames. The frames used were subjected to acceleration at the base by using three earthquakes (16] and seven earthquakes [17]. To obtain the maximum drift, displacement time histories, acceleration time histories, hysteresis, etc. for each one of the frames the program ETABS [19] and programs utilizing Mathlab applications was developed. The amount of damage was quantified by using HAZUS parameter $[14,15]$, where the damage index was obtained based on the ratio between the maximum displacement and the story height.

Finally, a series of Figures and Table are presented for each frame analyzed in order to represent the difference between using three [17] and seven [18] seismic records.

\section{EQUATION OF MOTION AND DAMPER FORCE}

It is well known that the equations of motion of a structure modeled as a multi-degree of freedom system and subjected to a base acceleration of $\ddot{x}_{g}(t)$ at all its supports is:

$$
[M]_{n \times n}\{\ddot{x}(t)\}+[C]_{n \times n}\{\dot{x}(t)\}+[K]_{n \times n}\{x(t)\}=-[M]_{n \times n}\{E\} \ddot{x}_{g}(t)
$$

where $[M],[C]$ y $[K]$ are the mass, damping and stiffness matrix respectively, the vectors $\{\ddot{x}(t)\},\{\dot{x}(t)\},\{x(t)\}$ are the acceleration, velocity and displacement of each dynamic degree of freedom of the structure, $\{E\}$ is the vector of influence coefficients, and $\mathrm{n}$ is the number of degrees of freedom. 
When a viscous fluid damper is incorporated in the structure, the damping matrix change. The force-displacement response of a velocity-dependent dashpot-type device is primarily a function of the relative velocity between each end of the device.

$$
[M]_{n \times n}\{\ddot{x}(t)\}+\left[C+C_{d}\right]_{n \times n}\{\dot{x}(t)\}+[K]_{n \times n}\{x(t)\}=-[M]_{n \times n}\{E\} \ddot{x}_{g}(t)
$$

The ideal force output of a viscous fluid damper can be expressed as is presented in equation (3).

$$
F_{d}(t)=C_{o}|\dot{x}(t)|^{\alpha} \operatorname{sgn}(\dot{x}(t))
$$

where $F d$ is the damper force, $C o$ is the damping coefficient for the device, $\dot{x}(t)$ is the relative velocity between each end of the device, sgn is the sign um function that in this case defines the sign of the relative velocity term, and $\alpha$ is the velocity exponent for the device which may take values in the range of about 0.25 to 2 (see reference [10]). The case $=1$ correspond to a linear viscous damper in which the damper force is proportional to the relative velocity. When smaller than 1 the device is called a nonlinear viscous damper. Values of larger than 1 (also a nonlinear damper) have not been used often in practical applications.

The viscous damping ratio in the first mode should be estimated as [7]:

$$
\beta_{v 1}=\frac{\sum_{j}(2 \pi)^{a_{j}} T_{1}^{2-a_{j}} \lambda_{j} C_{j} f_{j}^{1+a_{j}} \Delta_{r o o f}^{a_{j}-1} \phi_{r j}^{1+a_{j}}}{8 \pi^{3} \sum_{i}\left(\frac{\omega_{i}}{g}\right) \phi_{i 1}^{2}}
$$

where $\lambda j$ is a dimensionless parameter given by Equation 14 of Ramirez et al. [10] and all other terms have been defined by Whittaker et Al [7].

\section{NUMERICAL PROCEDURE AND EXAMPLE}

As an initial step, two concrete frames are established for two different buildings, Type I frame is five (5) levels with cover consisting of beams and columns with three lights ranging in length between $4 \mathrm{~m}$ and $5 \mathrm{~m}$ with a total height per story of $3 \mathrm{~m}$, on the other hand, the type II frame consists of seven (7) levels with cover and four lights ranging in length between $5 \mathrm{~m}$ and $6 \mathrm{~m}$ with total height per story of $3 \mathrm{~m}$, as shown in the Figure 1. 


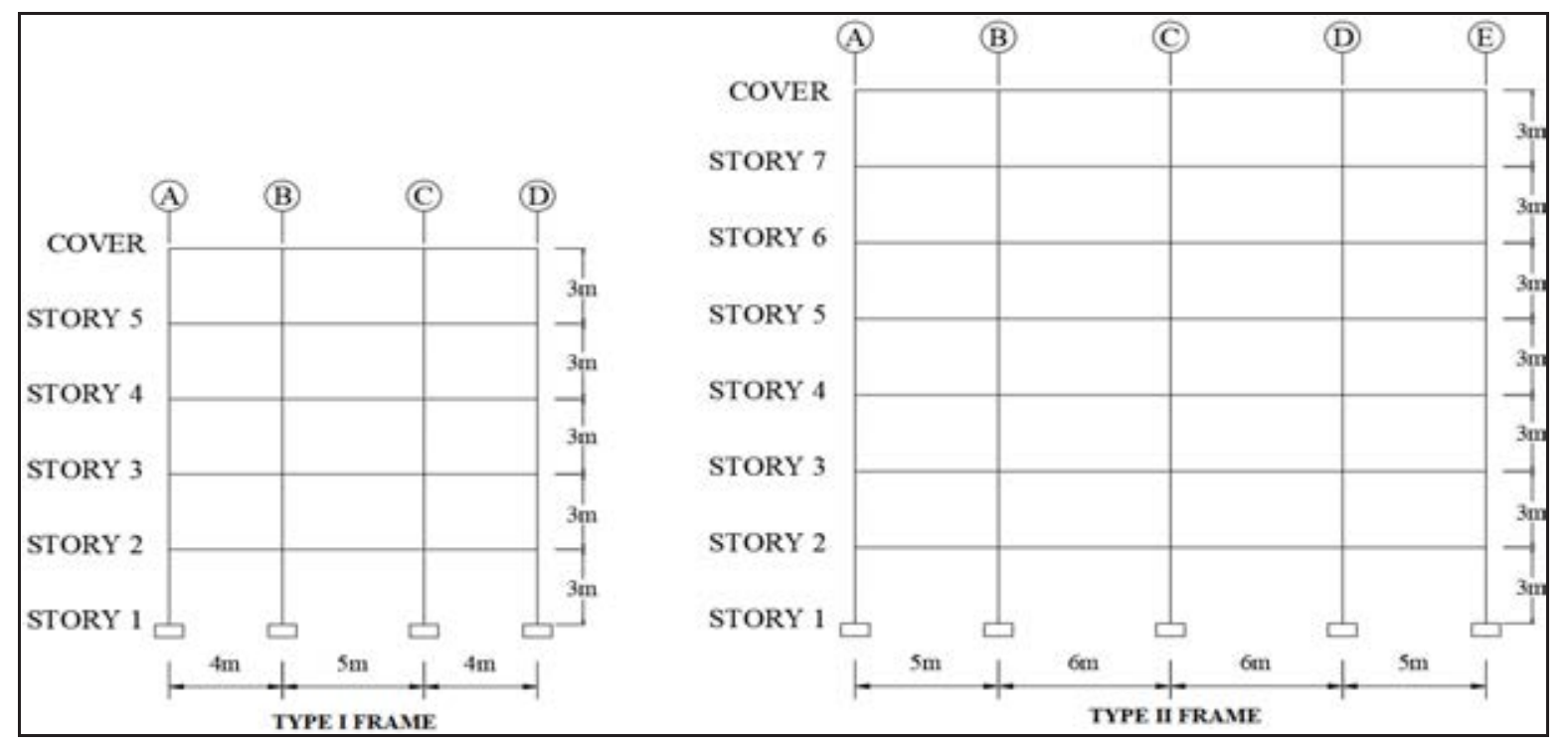

Figure 1: Types frames.

Once the two types of frames are defined to be designed, the next step is to build the design spectrum, where two types of spectrum with different characteristics belonging to a particular area were established, for this, the Colombian earthquake resistant code (NSR-10) was used. establishing the city of "Santiago de Cali" as the area to study because it is an area of high seismic threat, for the spectrum, different couples of results were taken depending on the importance level of the structure and of the type of soil, for the Type I design spectrum, a type "D" soil was used, corresponding to rigid soil profiles with a group III of importance equivalent to "Community care buildings". For the Type II design spectrum, a type "C" soil was used, corresponding to soft soil profiles or formed by soft rock, with a group IV of importance equivalent to "Essential buildings" such as clinics. Based on this data, the rest of the coefficients belonging to the construction of the design spectrum. The Table 1 presents the definitive characteristics for each type of spectrum.

\begin{tabular}{cccccccc}
\hline \multicolumn{7}{c}{ DESIGN SPECTRUM COEFFICIENTS } \\
\hline \hline ESPECTRUM & SOIL GROUP & Aa & Av & Fa & Fv & IMPORTANCE GROUP & I \\
\hline Type I espectrum & D & 0,25 & 0,25 & 1,3 & 1,9 & III & 1,25 \\
Type II espectrum & C & 0,25 & 0,25 & 1,15 & 1,55 & IV & 1,5 \\
\hline
\end{tabular}

Table 1: Design spectrum coefficients.

Once the spectrum coefficients are defined, it gives way to calculate and graph the two types of spectrum "Type I" and "Type II", therefore, the maximum expected spectrum "MCEr" is calculated, as indicated by the American regulations, multiplying by 1,5 the accelerations obtained in the previous calculated designs spectrum. Figure 1 shows the design spectrum. 


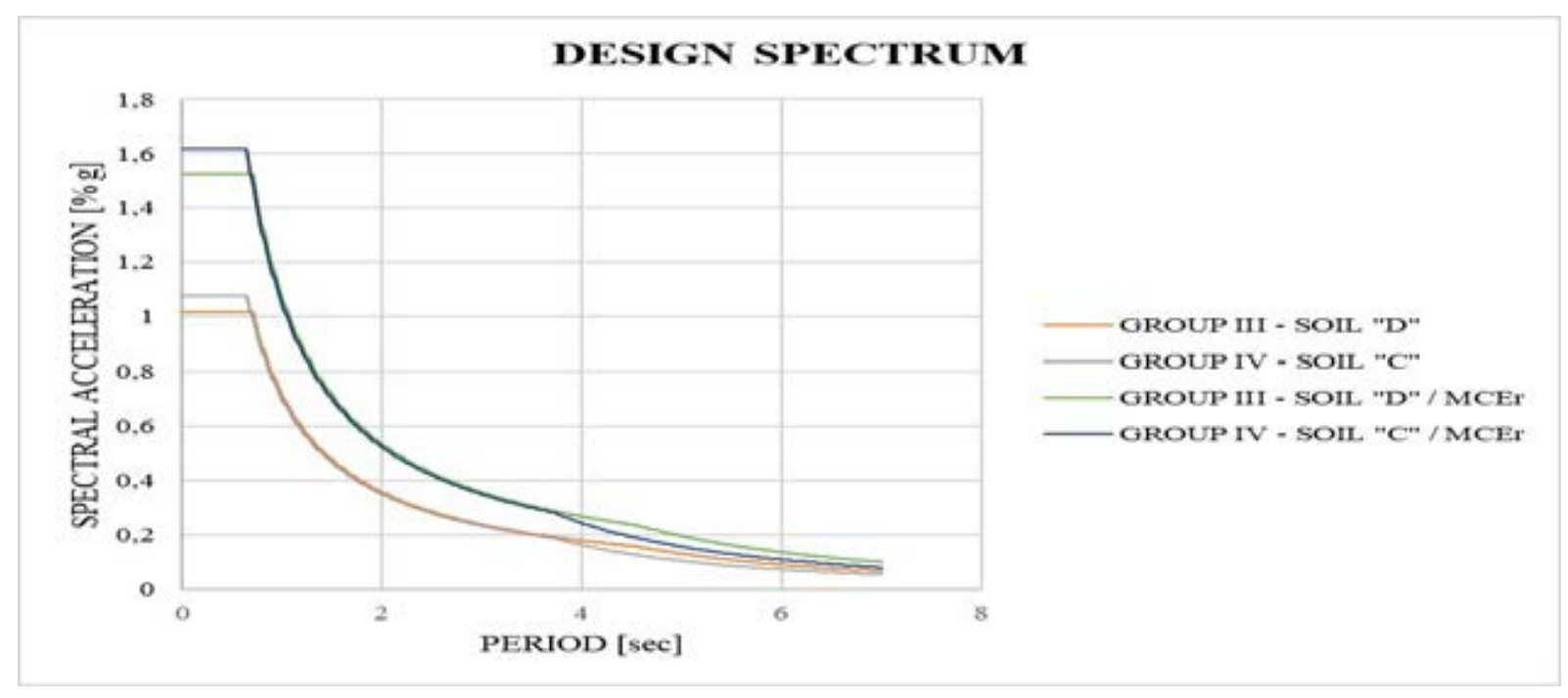

Figure 2: Design spectrum.

For the load assessment of the two frames, an afferent width of $3 \mathrm{~m}$ was assumed, a $10 \mathrm{~cm}$ slab and an additional dead load corresponding to walls with an equivalent value to $2 \mathrm{kN} / \mathrm{m}^{2}$, on the other hand, a live load was assumed for each story equivalent to $2,5 \mathrm{kN} / \mathrm{m}^{2}$ and $0,5 \mathrm{kN} / \mathrm{m}^{2}$ for the cover, therefore, the respective load assessment is obtained. The Table 2 presents the load assessment.

\begin{tabular}{cccc}
\hline \multicolumn{4}{c}{ LOAD ASSESSMENT } \\
\hline \hline FRAME & STOREYS & WD [KN/m^2] & WL $\left[\mathbf{K N} / \mathbf{m}^{\wedge} \mathbf{2}\right]$ \\
\hline Type I & $1-5$ & 4,4 & 2,5 \\
Type I & Cover & 2,4 & 0,5 \\
Type II & $1-7$ & 4,4 & 2,5 \\
Type II & Cover & 2,4 & 0,5 \\
\hline
\end{tabular}

Table 2: Load Assessment.

After obtaining the load assessment, it gives way to carry out the pre-dimensioning and design of the different structural elements for the two frames, thus obtaining the following dimensions. The Table 3 presents the model dimensions.

\begin{tabular}{|c|c|c|c|c|}
\hline \multicolumn{5}{|c|}{ MODEL DIMENSIONS } \\
\hline ESPECTRUM & TYPE FRAME BASE COLUMN (cm) & HEIGHT COLUMN (cm) & BASE BEAM $(\mathrm{cm})$ & HEIGHT BEAM $(\mathrm{cm})$ \\
\hline Group III - Soil D & 40 & 40 & 40 & 40 \\
\hline Group IV - Soil C & 55 & 55 & 55 & 50 \\
\hline
\end{tabular}

Table 3: Model dimensions.

The code ASCE 7-16 specifies that, for both the design spectrum and the MCEr, at least seven (7) seismic records must be selected, each of these records must be escalated to the design spectrum as the MCEr, the average of the seven (7) seismic records should not stay below both spectrums mentioned above. For this, the procedure called "Matching" is carried out using the SeismoMatch software [23], where a damping of 5\% is determined and the period of 
vibration of the structure is specified by the design spectrum and the MCEr. next up, the seven (7) seismic records to analyze. The Table 4 presents the seven (7) seismic records.

\begin{tabular}{cccc}
\hline \multicolumn{4}{c}{ SEISMIC RECORDS } \\
\hline \hline NAME & YEAR & MAGNITUDE & PGA [g] \\
\hline ChiChi & 1999 & 7,3 & 0,36 \\
Friuli & 1976 & 6,4 & 0,35 \\
El Centro & 1940 & 6,9 & 0,32 \\
Kobe & 1995 & 6,9 & 0,34 \\
Kocaeli & 1999 & 7,4 & 0,35 \\
Loma Prieta & 1989 & 6,9 & 0,37 \\
Nortrhidge & 1994 & 6,7 & 0,57 \\
\hline
\end{tabular}

Table 4: Seven seismic records.

On the other hand, the code ASCE 7-10, specifies that, for both the design spectrum and the MCEr, three (3) seismic records must be selected, unlike the standard ASCE 7-16, Each seismic record must be analyzed independently, analyzing the maximum values obtained for each record, without averaging the results of the three records among themselves. Since the objective is to compare the behavior in each frame for both seven (7) and three (3) registers, of the seven (7) mentioned above, three records are chosen to perform the respective calculations and analysis based on the ASCE 7-10. The Table 5 presents the three (3) seismic records to analyze.

\begin{tabular}{cccc}
\hline \multicolumn{4}{c}{ SEISMIC RECORDS } \\
\hline \hline NAME & YEAR & MAGNITUDE & PGA [g] \\
\hline Friuli & 1976 & 6,4 & 0,35 \\
Loma Prieta & 1989 & 6,9 & 0,37 \\
Nortrhidge & 1994 & 6,7 & 0,57 \\
\hline
\end{tabular}

Table 5: Seven seismic records.

Once the seismic records, design spectrum and dimensions mentioned above are defined, the modeling is carried out using the ETABS Software [19], where four (4) structural models are defined, and each one of the frames are evaluated by the method given by each code. Next up, the four (4) models to analyze. The Table 6 presents the model types.

\begin{tabular}{cccc}
\hline \multicolumn{4}{c}{ MODEL TYPES } \\
\hline \hline MODEL & FRAME TYPE & ESPECTRUM & METHOD \\
\hline I & I & Group III - Soil D & ASCE-16 \\
II & I & Group III - Soil D & ASCE-10 \\
III & II & Group IV - Soil C & ASCE-16 \\
IV & II & Group IV - Soil C & ASCE-10 \\
\hline
\end{tabular}

Table 6: Model types.

After assigning each model with different properties, it gives way to define the energy dissipaters, in this case, the viscous dampers were modeled as non-linear elements "Link" of the "Damper - Exponential" type, the dampers are located in the external lights of each frame. 
Next up, the distribution and selection of the dampers to be analyzed in each frame. The Figure 3 shows the Damper's location and selection.

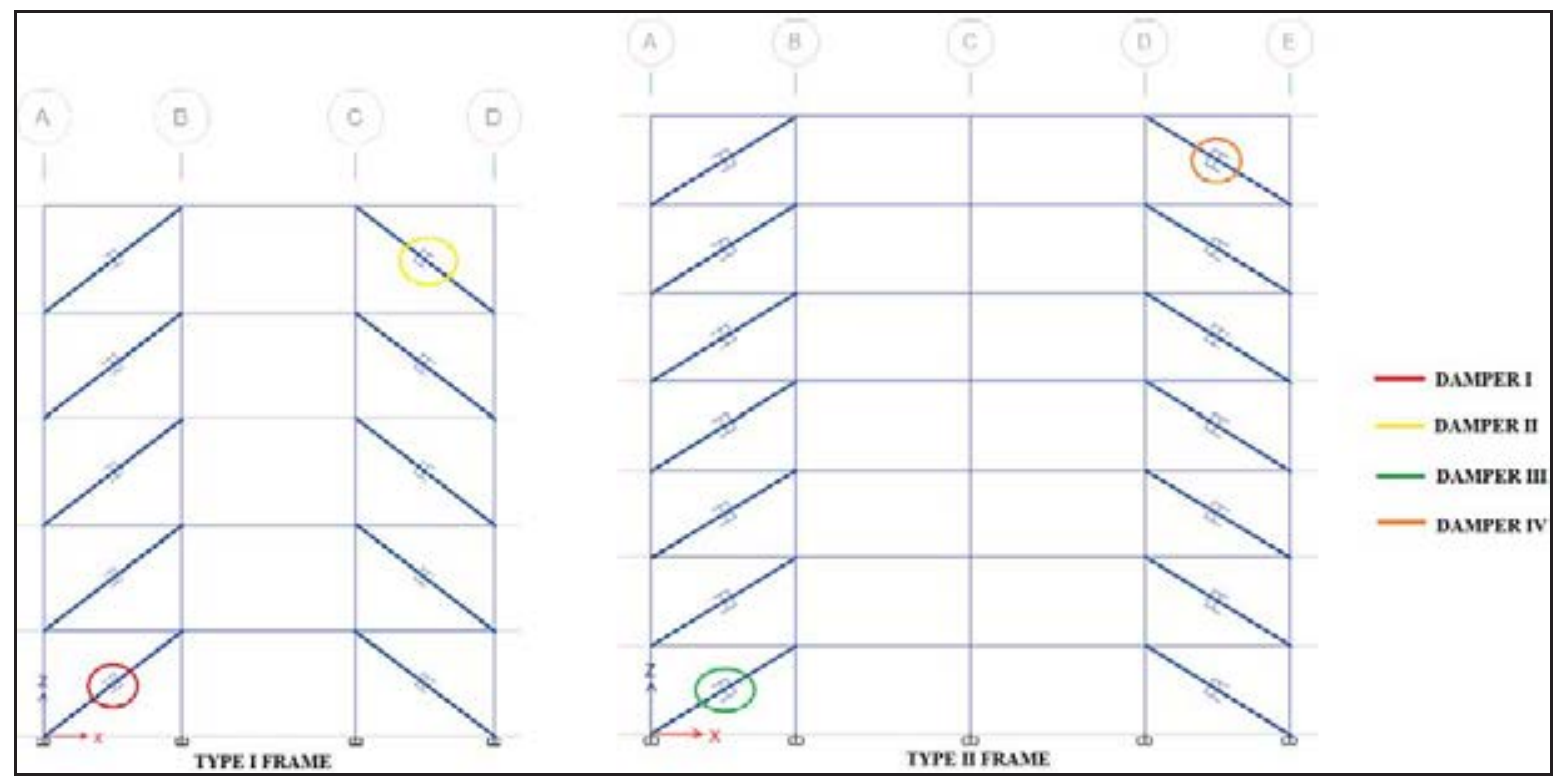

Figure 3: Damper's location and selection.

Each of the dampers are assigned a value of $(\alpha=0.3)$, on the other hand, the damping " $C$ " is included, which is generated by the damper, plus the contribution of the stiffness of the strut connecting the damper, depending on the stiffness value on the diagonal is assigned a metal profile equivalent to that value. Next up, the properties for each damper depending on the model to be analyzed. The Table 7 presents the viscous dampers properties.

\begin{tabular}{cllllc}
\hline \multicolumn{5}{c}{ VISCOUS DAMPERS PROPERTIES } \\
\hline \hline FRAME TYPE & ESPECTRUM & METHOD & PROFILE & STIFFNESS [KN/m] & DAMPING [KN*(s/m)^Cexp] \\
\hline I & Group III - Soil D & ASCE-16 & W8X24 & 200000 & 100 \\
I & Group III - Soil D & ASCE-10 & W8X31 & 250000 & 100 \\
II & Group IV - Soil C & ASCE-16 & W8X35 & 290000 & 100 \\
II & Group IV - Soil C & ASCE-10 & W8X35 & 290000 & 100 \\
\hline
\end{tabular}

Table 7: Viscous dampers properties.

Once each model has been defined with their respective properties for each damper, we proceed to run each of the models in order to analyze the behavior of each of these under the different methods established by the ASCE-10 and ASCE-16 codes. Since the code establishes that when designing a structure with energy dissipaters, said structure must be evaluated against different seismic records. When a structure is exposed to a seismic loading, the structure presents displacement generated by the force, the displacement is in function with the height, that is why the displacement at the maximum point of the structure is analyzed, in this case on the cover, due to this, the maximum displacements generated by each historical record are analyzed in order to analyze said displacements and see if these values are optimal for the structure. 
Then the seismic record is shown as in function of the time for the cover displacement in each one (1) of the four (4) models. The Figure 4 shows the cover displacement for Model I and Model II.
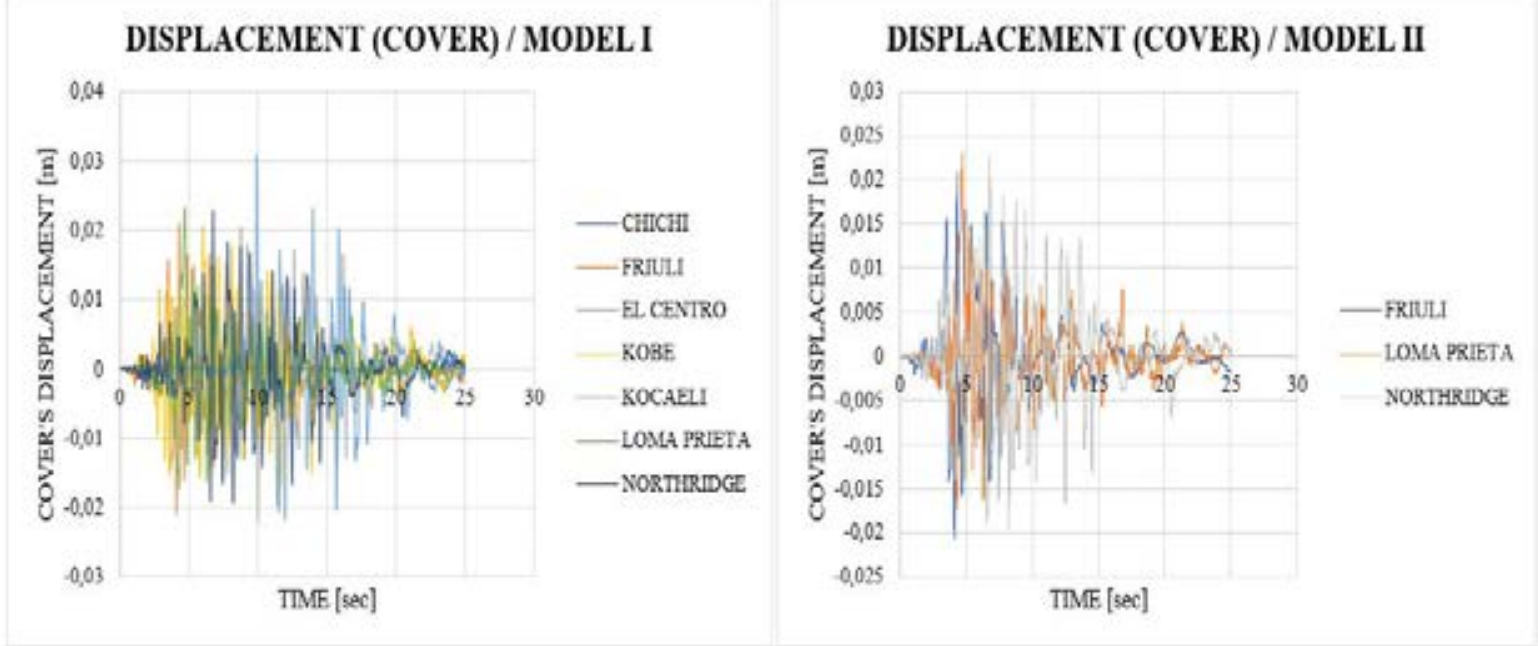

Figure 4: Cover displacement (MI - 7 seismic records vs MII - 3 seismic records).

With regard to "Model I" in Figure 4, it presents a maximum displacement on the cover equivalent to $0,031 \mathrm{~m}$ corresponding to the seismic record "Kocaeli", however, the average of the seven (7) seismic records presents a maximum displacement of $0,02 \mathrm{~m}$, on the other hand, the "Model II" presents a maximum displacement on the cover of $0,023 \mathrm{~m}$ corresponding to the "Loma Prieta" seismic record. The Figure 5 shows the cover displacement for Model III and Model IV.

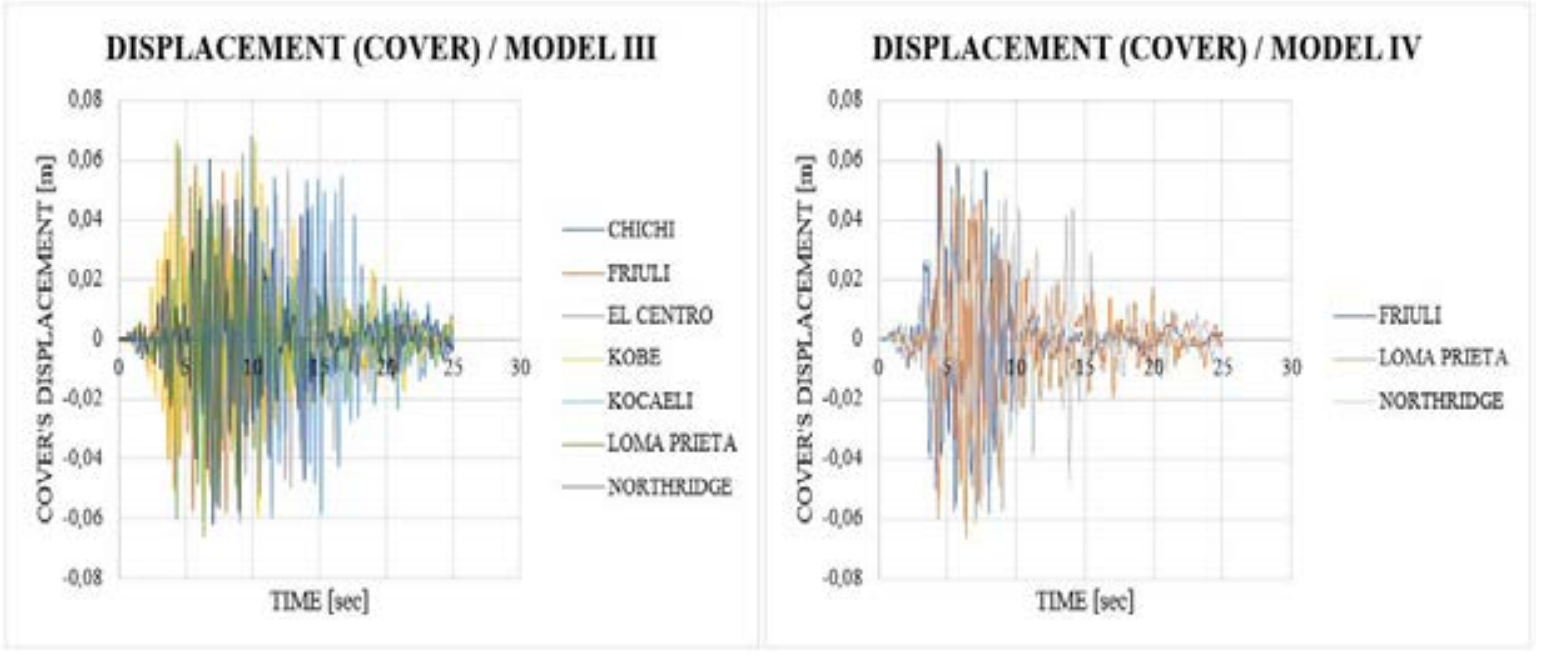

Figure 5: Cover displacement (MIII - 7 seismic records vs MIV - 3 seismic records).

It is observed that in Figure 5, the "Model III" presents a maximum displacement on the cover equivalent to $0,068 \mathrm{~m}$ corresponding to the seismic record "Kocaeli", however, the average of the seven (7) seismic records presents a maximum displacement of $0,057 \mathrm{~m}$, on the other hand, with regard to the "Model IV" this presents a maximum displacement on the cover of 0,066m corresponding to the "Loma Prieta" seismic record. 
The Table 8 presents the maximum cover displacements for each model.

\begin{tabular}{ccc}
\hline & \multicolumn{2}{c}{ DISPLACEMENT (COVER) } \\
\hline \hline MODEL & METHOD & MAXIMUM DISPLACEMENT [m] \\
\hline I & ASCE-16 & 0,02 \\
II & ASCE-10 & 0,023 \\
III & ASCE-16 & 0,057 \\
IV & ASCE-10 & 0,066 \\
\hline
\end{tabular}

Table 8: Maximum displacement.

Once the maximum displacements on the cover have been found, the corresponding drifts to each model is reviewed in order to analyze if these meet the requirements for design, based on the Methodology "HAZUS" a moderate damage is established for armed concrete frames, for the "Type I" frame with a total heigh of $15 \mathrm{~m}$, a target drift of $0,58 \%$ is assigned, on the other hand, for the "Type II" frame with a total heigh of $21 \mathrm{~m}$, a target drift of $0,54 \%$ is assigned as presented in the following table. The Table 9 presents the target drifts.

\begin{tabular}{|c|c|}
\hline TARGET & DRIFTS \\
\hline FRAME TYPE & DRIFTS [\%] \\
\hline I & 0,58 \\
\hline II & 0,54 \\
\hline
\end{tabular}

Table 9: Target drifts.

Based on the aforementioned, the same gantry is compared under the methodologies specified in each code. The Figure 6 shows the maximum story drifts for Model I and Model II.

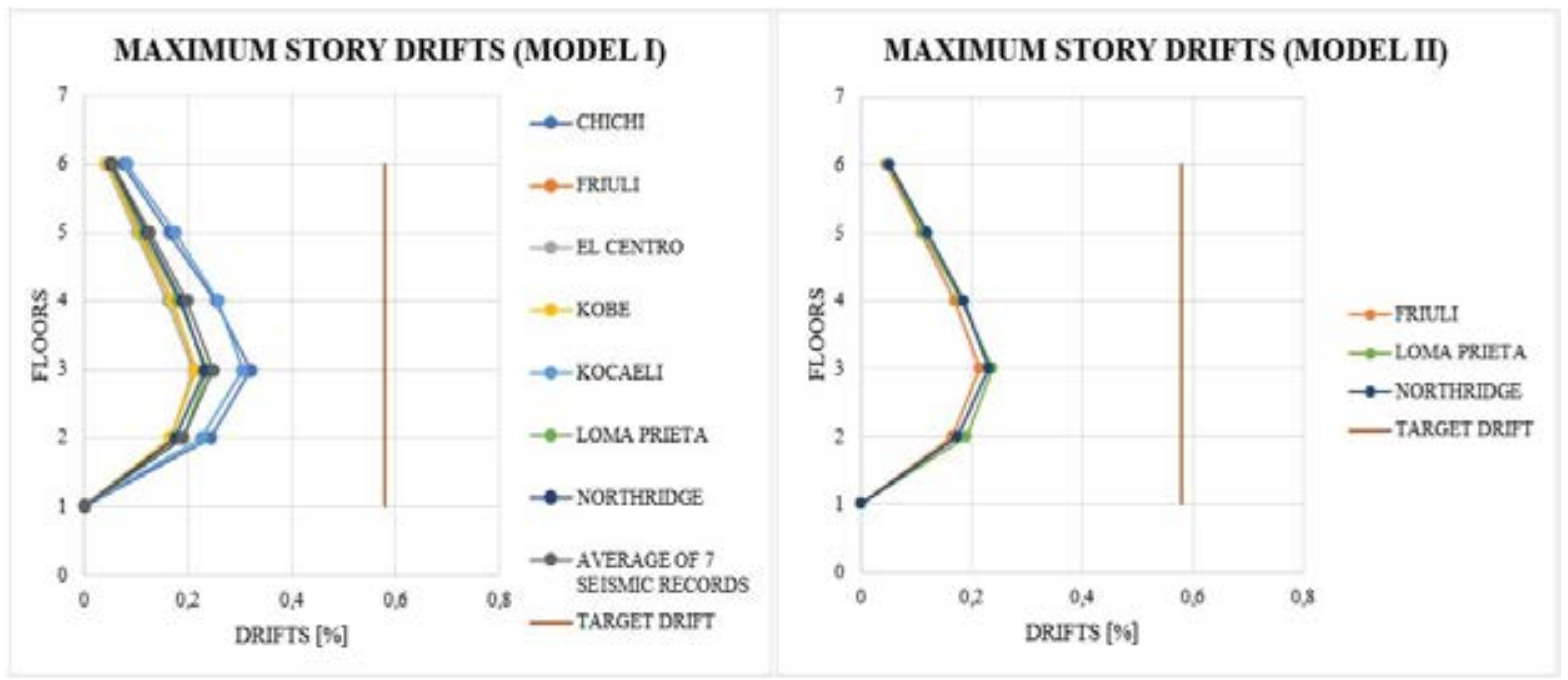

Figure 6: Maximum story drifts (MI - 7 seismic records vs MII - 3 seismic records).

As it can be seen in Figure 6, both models are below the target drift, on one hand, "Model I" presents a maximum equivalent drift to $0,32 \%$ corresponding to the "Chichi" seismic record, however, the average of the seven (7) seismic records shows a maximum drift of $0,25 \%$, on the other hand, the "Model II" presents a maximum drift of $0,24 \%$ corresponding to the 
"Loma Prieta" seismic record. The Figure 7 shows the maximum story drifts for Model III and Model IV.

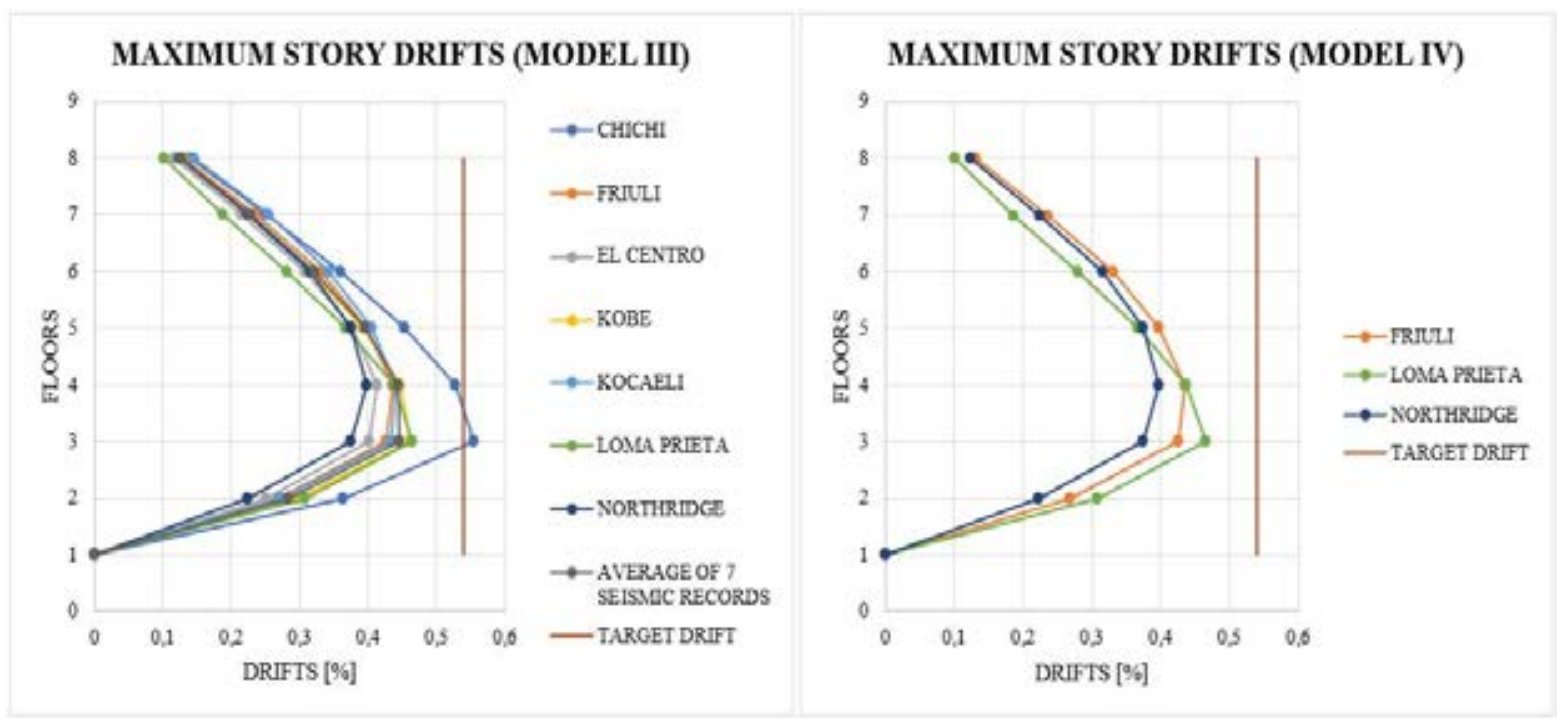

Figure 7: Maximum story drifts (MIII - 7 seismic records vs MIV - 3 seismic records).

In Figure 7, for the "Model III" it is observed that the "Chichi" seismic record exceeds the target drift with an equivalent value to $0,56 \%$, however, the average of the seven (7) seismic records presents a maximum drift of $0,45 \%$, on the other hand, the "Model IV" presents a maximum drift of $0,47 \%$ corresponding to the "Loma Prieta" seismic record.

The Table 10 presents the maximum drifts for each model.

\begin{tabular}{cccc}
\hline \multicolumn{4}{c}{ MAXIMUM STORY DRIFTS } \\
\hline \hline MODEL & \multicolumn{1}{c}{ METHOD } & DRIFT [\%] & TARGET DRIFT [\%] \\
\hline I & ASCE-16 & 0,25 & 0,58 \\
II & ASCE-10 & 0,24 & 0,58 \\
III & ASCE-16 & 0,45 & 0,54 \\
IV & ASCE-10 & 0,47 & 0,54 \\
\hline
\end{tabular}

Table 10: Maximum story drifts.

Therefore, considering the MCEr registers, the force-displacement relationship is analyzed in different dampers located on the first and last story. Next up, the Figure 8, 9, 10 and 11 show the dampers hysteresis cycle with different location in each frame. 

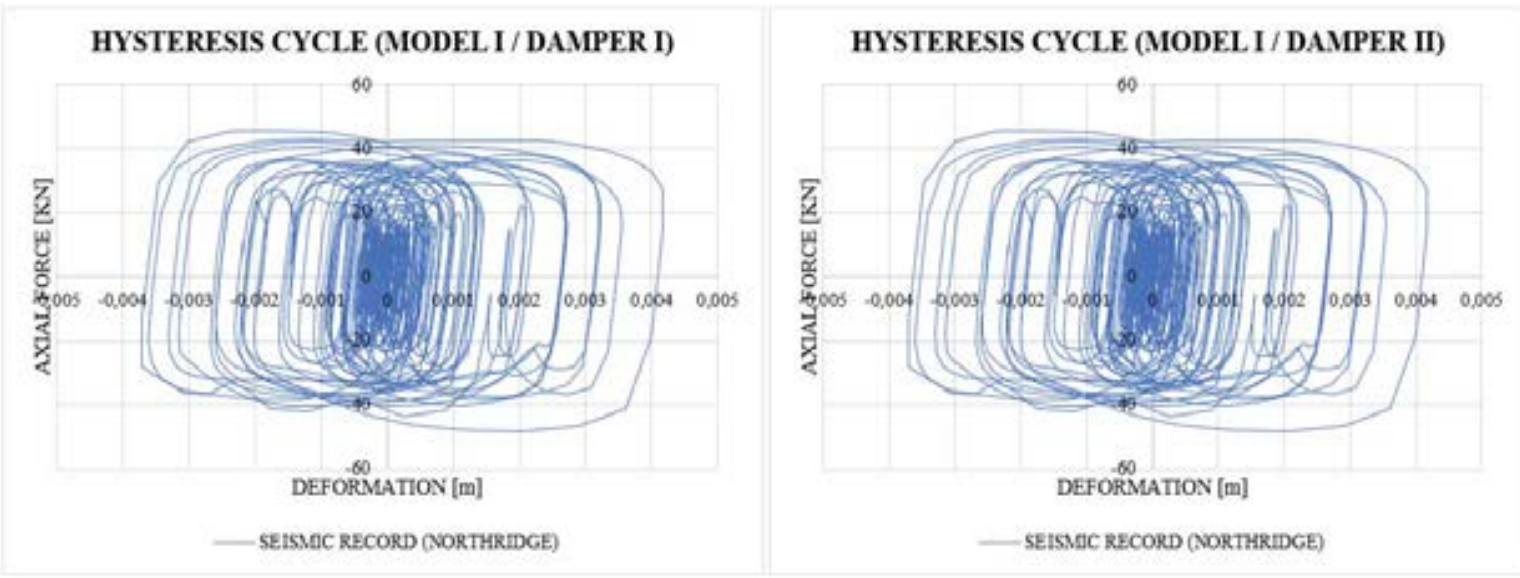

Figure 8: Model I hysteresis cycle.
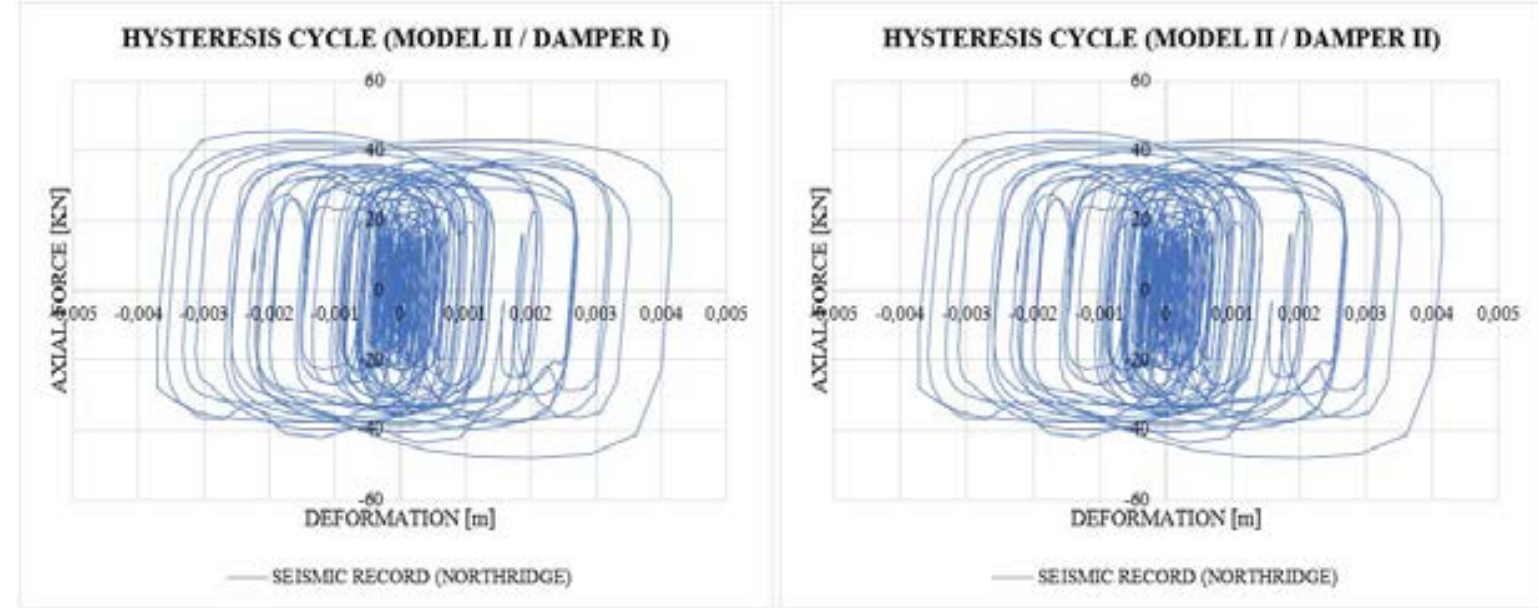

Figure 9: Model II hysteresis cycle.

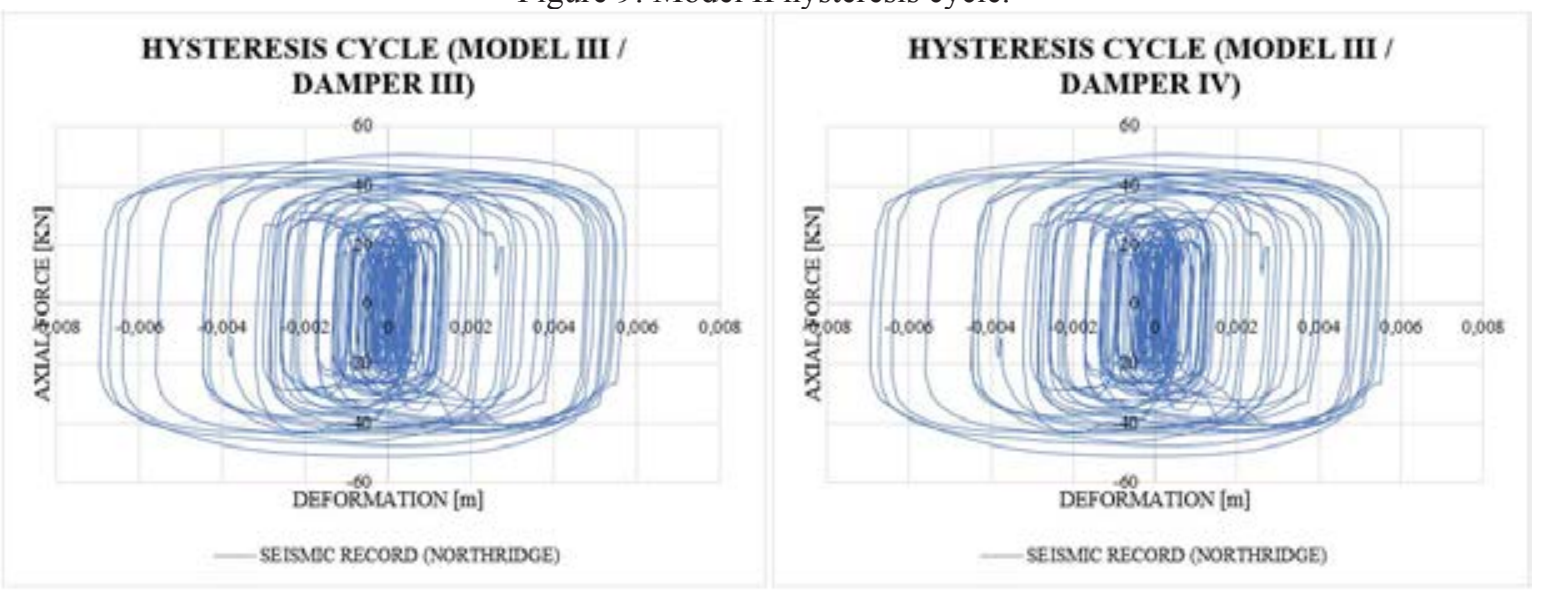

Figure 10: Model III hysteresis cycle. 

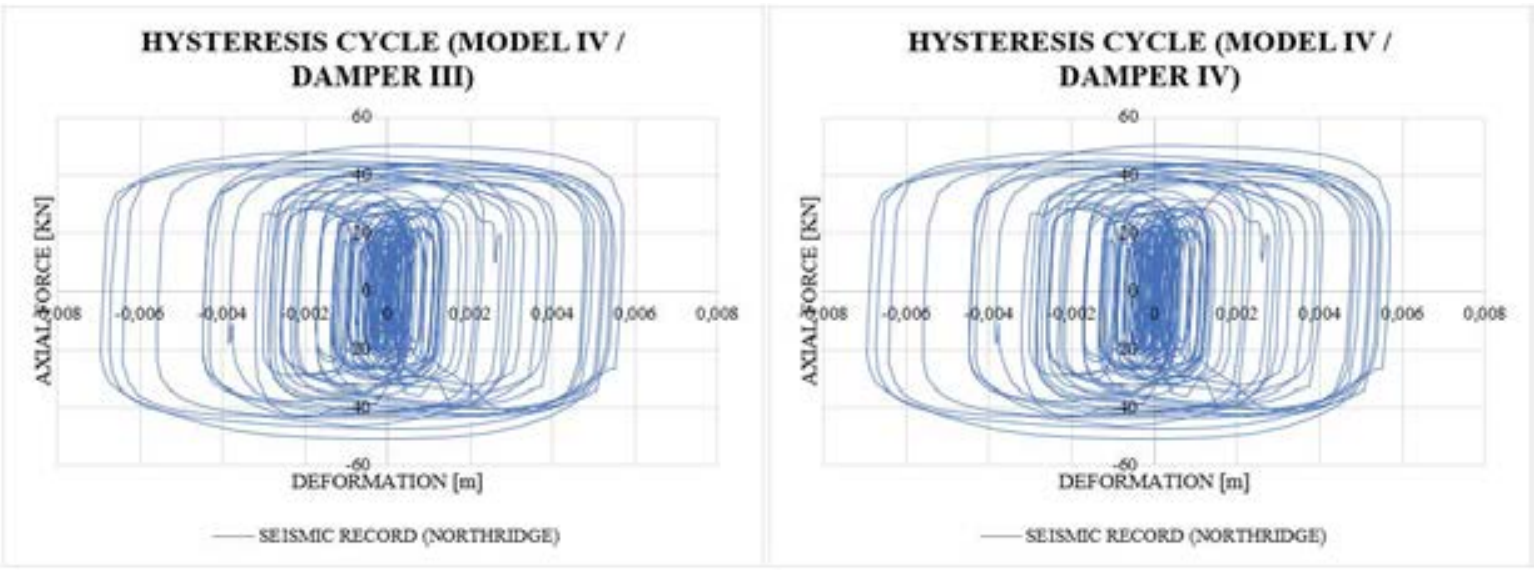

Figure 11: Model IV hysteresis cycle.

Finally, the results of the progressive accumulation of the shear forces in each story are presented, which are reflected in the same base, next up, the seismic record is shown as in function of the time for the base shear in each one (1) of the four (4) models. The Figure 12 shows the base shear results for Model I and Model II.

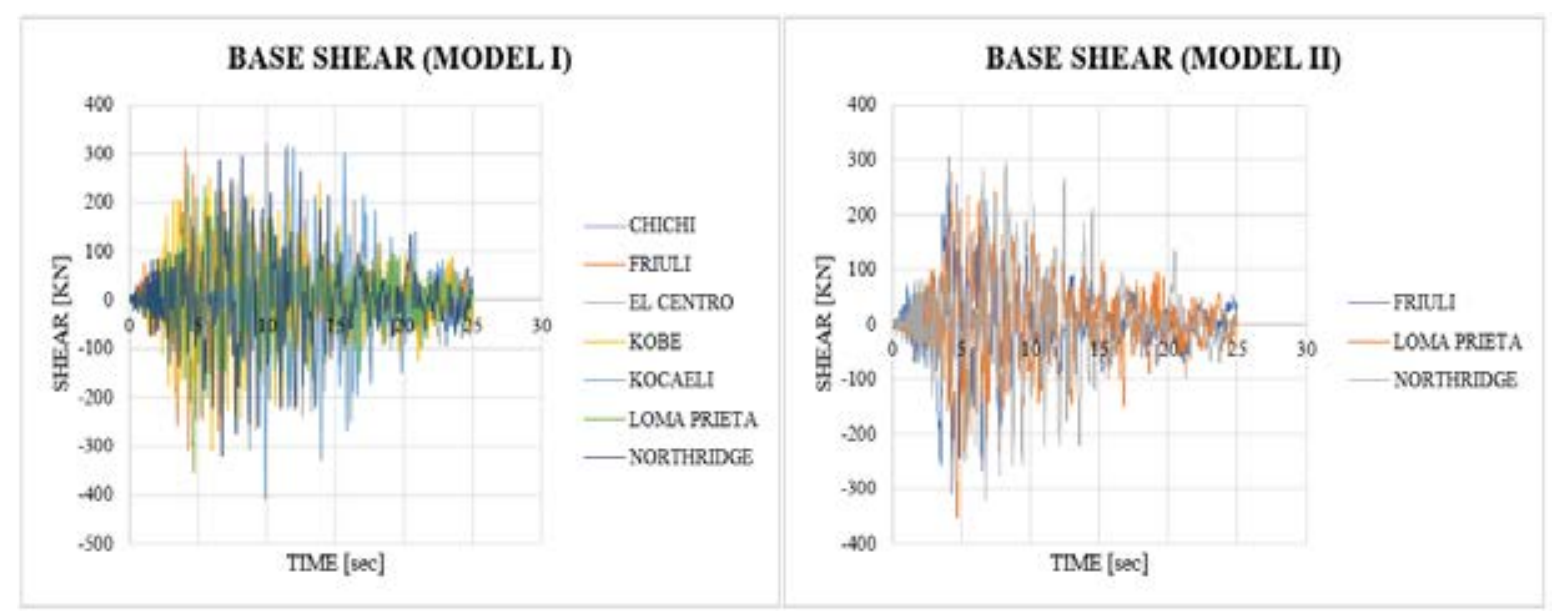

Figure 12: Base shear (MI - 7 seismic records vs MII - 3 seismic records).

With regard to "Model I" in Figure 12, it presents a maximum base shear with a value equivalent to $408,8 \mathrm{kN}$ corresponding to the seismic record "Kocaeli", however, the average of the seven (7) seismic records presents a maximum shear at the base with a value of $300,3 \mathrm{kN}$, on the other hand, the "Model II" presents a maximum base shear with a value of $351,9 \mathrm{kN}$ corresponding to the "Loma Prieta" seismic record. The Figure 13 shows the base shear results for Model III and Model IV. 


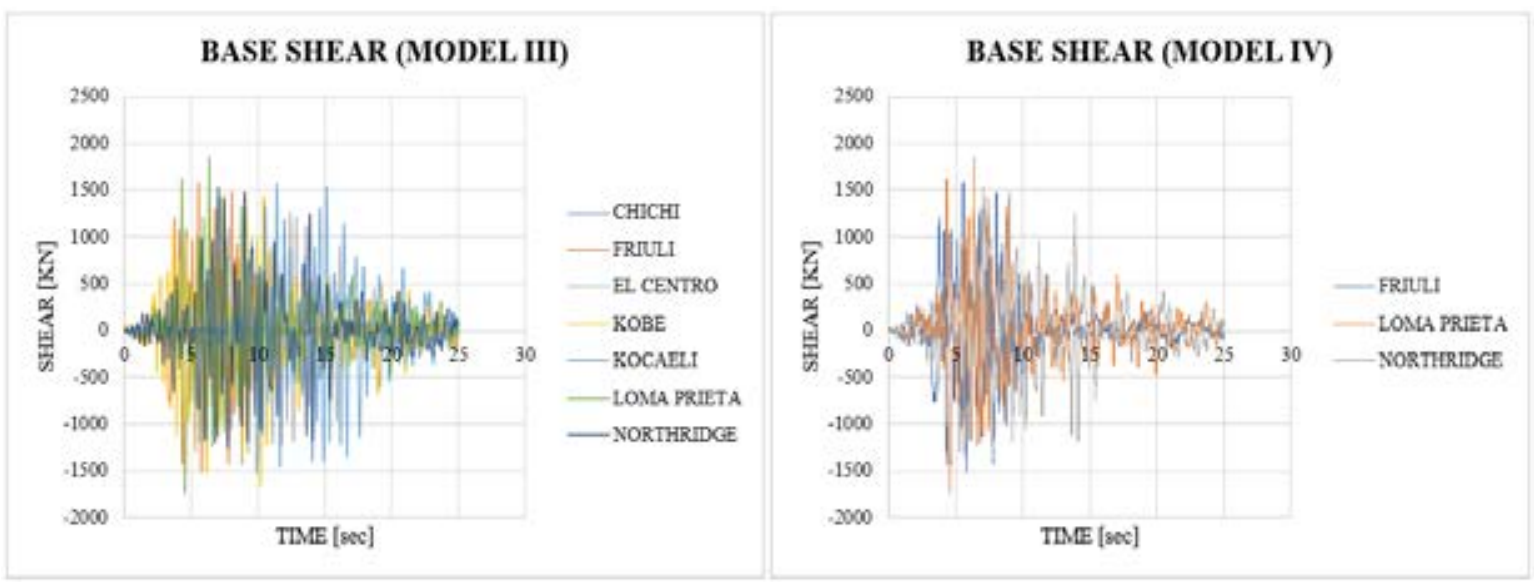

Figure 13: Base shear (MIII - 7 seismic records vs MIV - 3 seismic records).

It is observed that in Figure 13, the "Model III" presents a maximum base shear with a value equivalent to $1851,5 \mathrm{kN}$ corresponding to the "Loma Prieta" seismic record, however, the average of the seven (7) seismic records presents a maximum base shear with a value of $1407 \mathrm{kN}$, on the other hand, with regard to "Model IV" this presents a maximum base shear of $1851,7 \mathrm{kNm}$ corresponding to the seismic record "Loma Prieta".

The Table 11 present the maximum base shear values for each model.

\begin{tabular}{ccc}
\hline \multicolumn{3}{c}{ BASE SHEAR } \\
\hline \hline MODEL & METHOD & BASE SHEAR [KN] \\
\hline I & ASCE-16 & 300,3 \\
II & ASCE-10 & 351,9 \\
III & ASCE-16 & 1407 \\
IV & ASCE-10 & 1851,7 \\
\hline
\end{tabular}

Table 11: Base shear.

\section{CONCLUSIONS}

This paper presented the analysis and result for two concrete frame buildings with passive controllers incorporated using the methodologies ASCE 7-10 (three seismic record) and ASCE 7-16 (seven seismic records). The response of the hysteresis cycle, time histories displacement, acceleration, and base shear were compared for each analysis and corresponding frame. The differences between the two methodologies of the maximum responses obtained were presented in detail in section 3.

The results obtained in the numerical simulations for the frames presented in this article, show in Table 8 differences in the maximum displacement of $15 \%$ in the two frames using both methodologies, the displacement results obtained are lower with the methodology of the ASCE 7-16. Similarly, Table 10 presents difference percentages of less than 5\% for the maximum drifts, registering the lowest values with the ASCE 7-16 methodology. 


\section{REFERENCES}

[1] Constantinou, M. C., Soong, T. T. \& Dargush, G. F. "Passive energy dissipation systems for structural design and retrofit" in Multidisciplinary Center for Earthquake Engineering Research-MCEER, University at Buffalo, Buffalo, New York.1998.

[2] Soong,T.T. “Active Structural Control: Theory and Practice”, John Wiley \& Sons, New York City, New York, 1990.

[3] O. Cundumí Sánchez, "Nonlinear Analysis of Structures Controlled With A New Variable Damping Device," in 14th World Conference on Earthquakes Engineering 14WCEE 2008, 2008.

[4] O. Cundumí Sánchez and L. E. Suárez, "A New Variable Damping Semi-Active Device Seismic Response Reduction of Civil Structure," J. Mech. Mater. Struct., vol. 2, no. 8, 2007.

[5] O. Cundumí Sánchez and S. Laboy, "Nonlinear Analysis of Structures Controlled with Passive Damper," in 17th Congreso de Ingeniería Sísmica, 2009.

[6] O. Cundumí Sánchez and S. Laboy, "Fragility Curves for Concrete Frame Buildings with Passive Controllers," in 9th US National and 10th Canadian Conference on Earthquake Engineering: Reaching Beyond Borders, 2010.

[7] Andrew S. Whittaker et Al, "Equivalent Lateral Force and Modal Analysis Procedures of the 2000 NEHRP Provisions for Buildings with Damping Systems", Earthquake Spectra, Vol. 19, no. 4, pages 959-980, November 2003.

[8] Ramirez, O. M., Constantinou, M. C., Kircher, C. A., Whittaker, A. S., Johnson, M. W., and Gomez, J. D. "Development and Evaluation of Simplified Procedures for Analysis and Design of Buildings with Passive Energy Dissipation Systems", MCEER Report 00-0010. Multidisciplinary Center for Earthquake Engineering Research, University at Buffalo, StateUniversity of New York, Buffalo, NY, 2000.

[9] Ramirez, O. M., Constantinou, M. C., Gomez, J. D., Whittaker, A. S., and Chrysostomou, C. Z.. "Elastic and inelastic seismic response of structures with damping systems", Earthquake Spectra 18 (3), 501-530.University at Buffalo, StateUniversity of New York, Buffalo, NY, 2002a.

[10] Ramirez, O. M., Constantinou, M. C., Whittaker, A. S., Kircher, C. A., and Chrysostomou, C. Z., 2002b. "Evaluation of simplified methods of analysis of yielding structures with damping systems“, Earthquake Spectra 18 (3), 531-547, 2002 b.

[11] Hrovat, D., Barak, P., and Rabins, M. "Semi-active versus passive or active tuned mass dampers for structural control". Journal of Engineering Mechanics, ASCE, Vol. 109, No. 3, pp. 691-705, (1983).

[12] Symans, M., and Constantinou, M. C. "Seismic testing of a building structure with a semi-active fluid damper control system". Earthquake Engineering and Structural Dynamics. Vol. 26, No. 7, pp. 759-777, (1997).

[13] Taylor, E., and Dyke, S. "The Development of Fragility Relationships for Controlled Structures", Master Thesis, Washington University, 2007.

[14] HAZUS-MH MR1., 2003. Multi-Hazard Loss Estimation Methodology: EarthquakeModel, Department of Homeland Security, FEMA, Washington, D.C. 
[15] Federal Emergency Management Agency (FEMA), "HAZUS-MH MR4 Multi-Hazard Loss Estimation Methodology - Earthquake Model: Technical Manual. Department of Homeland Security," Fed. Emerg. Manag. Agency, Washington, ..., 2003, [Online]. Available: www.fema.gov/plan/prevent/hazus.

[16] Asociación Colombiana de Ingeniería Sísmica, Requisitos generales de diseño y construcción sismo resistente, vol. Titulo A. 2010.

[17] American Society of Civil Engineers, ASCE Standard ASCE/SEI 7-10, 2010.

[18] American Society of Civil Engineers, ASCE 7-16, vol. 69, no. 1782. 2017.

[19] I. Computers \& Structures, "ETABS User's Guide." 2019.

[20] Departamento Administrativo de Gestión del Medio Ambiente DAGMA and Instituto Colombiano de Geología y Minería INGEOMINAS, "Estudio de Microzonificación Símica de Santiago de Cali. Convenieo 002 de 2002,” 2002.

[21] C. F. Grajales, I. F. Otálvaro, and O. Cundumi, "Efectos de horizontes de suelos blandos profundos en la respuesta dinámica del campus de la PUJ Cali," in IX Congreso Nacional de Ingeniería Sísmica, 2020.

[22] J. Hancock, J. J. Bommer, and P. J. Stafford, "Numbers of scaled and matched accelerograms required for inelastic dynamic analyses," Earthq. Eng. Struct. Dyn., vol. 37, no. 14, pp. 1585-1607, Nov. 2008, doi: 10.1002/eqe.827.

[23] Seismosoft, "SeismoMatch - A computer program for spectrum matching of earthquake records," vol. 0. 2020.

[24] Federal Emergency Management Agency, Improvement of Nonlinear Static Seismic Analysis Procedures, vol. 440, no. June. 2005.

[25] Federal Emergency Management Agency FEMA 356, Prestandard and Commentary for the Seismic Rehabilitation of Buildings, no. November. 2000.

[26] Taylor Devices Inc., Fluid Viscous Dampers General Guidelines for Engineers Including a Brief History. 2020.

[27] Seismic design of buildings with passive energy dissipation systems - Requirements and test methods. NCh3411, 2017.

[28] ATC/BSSC. NEHRP Commentary on the Guidelines for the Seismic Rehabilitation of Buildings, FEMA 274 Report, prepared by the Applied Technology Council for the Building Seismic Safety Council, Federal Emergency Management Agency, Washington, DC, $1997 b$.

[29] ATC-13. Earthquake Damage Evaluation Data for Californa, Report No. ATC-13, Applied Technology Council, Redwood City, California, 1985.

[30] EUROCODES Building the Futures. European Commission. 